\title{
Land sharing vs land sparing to conserve biodiversity: How agricultural markets make the difference
}

\author{
Marion Desquilbet, ${ }^{\mathrm{a}}$ Bruno Dorin, ${ }^{\mathrm{b}, \mathrm{c}} \&$ Denis Couvet ${ }^{\mathrm{d}}$ \\ a Toulouse School of Economics, INRA, University of Toulouse Capitole, Toulouse, France. \\ 21 allée de Brienne, 31015 Toulouse Cedex 6, France. \\ ${ }^{\mathrm{b}}$ CIRAD, UMR CIRED, 73 rue J.F. Breton, 34398 Montpellier, France. \\ ${ }^{\mathrm{c}}$ CSH, UMIFRE MAE-CNRS, 2 Aurangzeb Road, New Delhi 110011, India. \\ ${ }^{\mathrm{d}}$ UMR CESCO MNHN-CNRS-UPMC, 55 rue Buffon, 75005 Paris, France. \\ *Corresponding author: marion.desquilbet@toulouse.inra.fr \\ Phone (+33) 561128578 . Fax (+33) 561225563.
}

\begin{abstract}
In this paper, we model the supply and demand for agricultural goods and assess and compare how welfare, land use and biodiversity are affected under intensive and extensive farming systems at market equilibrium instead of at exogenous production levels. As long as demand is responsive to price, and intensive farming has lower production costs, there exists a rebound effect (larger market size) of intensive farming. Intensive farming is then less beneficial to biodiversity than extensive farming, except when there is a high degree of convexity between biodiversity and yield. On the other hand, extensive farming leads to higher prices and smaller quantities for consumers. Depending on parameter values, it may increase or decrease agricultural producer profits. Implementing "active" land sparing by zoning some land for agriculture and other land for conservation could overcome the rebound effect of intensive farming, but we show that farmers have then incentives to encroach on land zoned for conservation, with higher incentives under intensive farming. We also show that the primary effect of the higher prices associated with extensive farming is a reduction of animal feed production, which has a higher price elasticity of demand, whereas less of an effect is observed on plant-based food production and almost no effect is observed on biofuel production if there are mandatory blending policies.
\end{abstract}

Keywords: biodiversity; conservation; agriculture; land use; markets; welfare 


\section{Introduction}

There is now abundant evidence showing a loss of global biodiversity [1, 2], and agriculture is a major cause of these losses [3, 4] because of its spatial expansion [5] and intensification [6]. This trend is expected to continue with the ever-increasing demand for agricultural food, feed, fiber, and energy that is projected for the coming decades [7, 8]. Based on the unequivocal evidence that a loss of biodiversity can affect ecosystem functioning, productivity, and resilience as well as biogeochemical cycles $[9,10]$, alleviating the impact of agriculture on biodiversity is a major concern for human societies.

An important part of the scientific and political debate on biodiversity and agriculture in the past decade has revolved around discussions, analyses, applications, and extensions of the land sparing versus land sharing framework proposed by Green et al. [11]. These authors have reinvestigated the "Borlaug hypothesis," in which yield-increasing technologies (such as those of the Green Revolution supported by Norman Borlaug) save land to prevent deforestation for instance [12-16]. Indeed, Green et al. have analyzed the extent to which agriculture should focus on intensively farmed land to conserve additional biodiversity-rich natural spaces elsewhere (land sparing) or on wildlife-friendly but less productive practices that conserve fewer wild natural spaces elsewhere (land sharing).

To this end, Green et al. [11] have built a theoretical model that compares the overall biodiversity level obtained from a high-yield farming system versus a low-yield farming system when a given production target must be met, and they have assumed (as we do in this paper) that land quality is homogenous, biodiversity can be captured by a single indicator, and biodiversity per unit of land is a decreasing function of the agricultural yield (the higher the yield, the lower the biodiversity on the same unit of land). The original and noteworthy contribution of Green et al. is their discussion of the issues at stake according to the shape of this decreasing function. If the relationship between biodiversity and yield is a linear function, then the two farming system archetypes lead to the same loss of biodiversity. However, if the relationship is convex, then biodiversity decreases by a high amount on any natural land that is converted to agriculture and extensive farming leads to an overall greater loss of biodiversity than intensive farming, whereas if the relationship is concave, the opposite results are observed. According to Green et al., the available empirical data from a range of taxa in developing countries support a convex relationship and therefore the land sparing strategy. Phalan et al. [17] have reached a similar conclusion after comparing the densities of trees and birds for different agricultural intensities in Ghana and India.

Green et al.'s [11] model and results have been subject to intense discussion and debate among scientists, notably ecologists (for a review, see Fischer et al. [18]). One dimension of this discussion, and the one our paper will investigate further, pertains to the fixed production target used for comparing the two farming system archetypes. In their introduction, Green et al. state that the world food demand is expected to more than double by 2050 , and they wonder how this enormously increased demand can be met at the least cost to biodiversity. This method of posing the problem has been debated on two main grounds. First, food security is not necessarily ensured by a high level of food production. Currently, food insecurity and food malnutrition (including over-nutrition) are more closely related to distribution and regular access to quality and balanced food than production, especially because a significant part of the current production is used to feed animals and to produce biofuels or wasted [19-21]. Second, the intensification of agriculture could provide incentives for its expansion, which would then limit effective land sparing for conservation [22-24]. 
Such a rebound effect, or Jevons paradox, may indeed occur if intensified agriculture allows productivity gains that lower prices and in turn encourage higher consumption and production levels [25]. In the face of such pressure, the effectiveness of land sparing is then contingent on the implementation of conservation zones (or protected areas), as emphasized by Green et al. [11], Ewers et al. [26], Phalan et al. [27], Balmford et al. [28] and Phalan et al. [29]. However, as noted by Fischer et al. [19], many countries lack the means to effectively protect such areas.

A second dimension of the debate on land sparing and sharing (LSS) pertains to the assumptions of Green et al. on the relationship between yield and biodiversity, although this dimension is beyond the scope of our work. Four issues have been raised in the literature. First, agricultural yields are not independent from the level of biodiversity as assumed in the model. Biodiversity can indeed positively affect agricultural yields by providing better and more resilient local climate conditions, as well as higher services, such as pollination, biological control, and soil fertility [30-33]. Second, the relationship between biodiversity and yield may not necessarily be negative. This negative relationship is adequate in the case of industrial agriculture that specializes in few cultivated plants or domesticated animals whose production is controlled and increased through the use of external inputs (chemical fertilizers, genes, pesticides, antibiotics, etc.). However, as documented by Clough et al. [34], a positive relationship between biodiversity and yield characterizes the intensification path that relies on ecological functions and biological synergies between many plant and animal species, such as in agroecology [35] and ecological intensification [36, 37]. To encompass both intensification paths, it would then be necessary to model different biodiversity-yield relationships between conventional intensive agriculture and ecologically intensive agriculture, as suggested by Tscharntke et al. [21] (Figure 1, p. 54). Third, the conventional intensification path of agricultural production over the past half century has had negative effects on biodiversity and on water, soil and air quality [38]. These costs affect human health and security and are a considerable burden to high-yielding industrial agriculture. Fourth, Green et al. consider a single indicator of biodiversity and Phalan et al. [17] consider two indicators (the abundance of trees and birds), whereas a higher diversity of indicators is required, because many other plant and animal species (including belowground species) play a key role in the provision of ecosystem services, as does the genetic diversity within each species [18, 21].

Although the literature provides an extensive discussion of all of the above issues, it rarely examines them through an analytical model. Similar to Green et al. [11], we believe that providing such an analytical framework is useful for clarifying the issues at stake. In this article, we propose an ecological and economical analytical model that addresses the first dimension of the discussion: the limitations induced by the assumption of an exogenous production target when comparing LSS strategies. To keep the model as simple and tractable as possible and to investigate the precise underlying mechanisms, our model uses the simple but debatable relationship between biodiversity and yield of the initial LSS framework (second dimension of the discussion). Additional realism and complexity may be added in a subsequent step.

To provide a formal model capable of analyzing the limits of comparing LSS strategies for a given production target, we introduce price as an adjustment mechanism between agricultural supply and demand. With this price adjustment, if extensive farming has a higher cost per unit of production (and a fortiori per unit of land), then extensive farming can reach the production level of intensive farming only if farmers receive a higher price, which drives the demand downwards until a new market equilibrium is reached. Overall, we compare the level of biodiversity obtained with each farming system when prices, production and 
consumption levels are the endogenous outcomes of market equilibrium. The effect on global welfare then depends on the relative weights attached to producer and consumer surpluses on one hand and to biodiversity conservation on the other.

This article is related to other works that have introduced an economic dimension into the LSS framework. Hart et al. [39] theoretically investigate the less costly solution to reach a minimum target of wild nature and use numerical simulations on bird reproduction from mown grasslands in Sweden. Their model examines the first-best allocation of farm practices that minimizes the costs of reaching a minimum wildlife target and does not include prices or market incentives. These authors show that when wildlife production entails a fixed cost on each unit of land, the optimum is likely a split solution in which certain farms pursue highintensity production while others produce less for the sake of nature. In such production systems, policies that encourage the development of specialist environmental providers may perform better than the current environmental schemes of the European Common Agricultural Policy, for example. With an economic simulation model of market supply and demand, Hertel et al. [40] examine the extent to which a green revolution in Africa is likely to be land and emission sparing compared with a counterfactual world that does not include the innovations of prior green revolutions in Asia, Latin America and the Middle East. Our framework is simpler and less ambitious empirically, but it is related to their analysis of market adjustment caused by changes in agricultural productivity and has the additional intent of relating market effects explicitly to the original focus of the LSS framework, or biodiversity change. Martinet [41] uses a three-class land-use model (biological reserve, wildlife-friendly agriculture, and intensive agriculture) to show that LSS strategies are not necessarily mutually exclusive when agricultural productivity is heterogeneously spatially distributed. Indeed, it may be in the interest of farmers and collectively optimal to allocate land with high productivity to intensive farming, with intermediate productivity to extensive farming, and with low productivity to natural reserves. This optimal land allocation may be attained by a mix of policies that combine input use taxes to control intensity and natural reserve subsidies to promote conservation. This model introduces producers' incentives but not price or welfare effects. Finally, the market and welfare framework developed by Meunier [42], which is closer to ours, explores a different range of questions by characterizing the optimal intensification level for a given marginal value of biodiversity, assessing the secondbest policies when the optimal policy cannot be implemented, and then showing that policy recommendations that are a priori optimal in a first-best setting may not be optimal in a second-best context.

Compared with the above economic works, our research investigates in detail how the LSS strategy is affected when intensive and extensive farming practices are compared at market equilibrium rather than at a given production target. We first present our theoretical framework along with its assumptions (section 2), and we then run our model to show the rebound effect of agricultural intensification in three different ways. The intuition of this rebound effect is shown by a graphic analysis. An analytical resolution of our model is then performed to formally demonstrate the set of situations under which the consideration of market effects reverts the initial LSS result. Numerical simulations are then performed to illustrate that our results are relevant even in a context where the price elasticity of demand for agricultural products is low, as suggested by the available empirical evidence (section 3). We then extend the model to further investigate two important questions raised by the initial LSS framework (section 4). First, we explore the extent to which "active" land sparing that consists of land-use zoning to counteract the rebound effect of agricultural intensification creates incentives for farmers to encroach on conservation zones. Second, we indirectly 
introduce certain elements of the LSS debate related to food security by distinguishing three goods: plant-based food products, feed used for animal-based food and biofuel products.

Our results show that even with a convex relationship between biodiversity and yield, biodiversity may be higher with extensive farming rather than intensive farming. The lower profitability of extensive farming leads to higher market prices and, therefore, to lower demand and production than with intensive farming. Consequently, agricultural land use increases to a lower extent than with a constant level of production and could even decrease in certain situations. Extensive farming is therefore favorable to biodiversity in many more cases than in the initial LSS framework. However, consumer surplus necessarily decreases, as does the sum of consumer and producer surplus, while producer surplus may either increase or decrease. Extensive farming could also decrease the agricultural pressure on conservation zones by reducing farmer incentives to encroach on these areas. The feed and animal products market, which has higher price elasticity, could be reduced and biofuel production could be almost unchanged with current mandatory blending policies. The differences between extensive and intensive farming do not show straightforward effects on food security because increased food prices provide better revenues for poor farmers and better ecosystem services for agriculture and society.

\section{Theoretical framework}

Similar to Green et al. [11], we compare a high yield scenario (land-sparing conventional intensive farming) with a lower yield scenario (wildlife-friendly extensive farming). As such, this stylized representation can account for two contrasting agricultural systems: (i) agro-industrial systems based on large farms that are highly mechanized with powerful motorized machinery and specialized in a few monocultures (or a single animal species) and present a high use of chemical inputs (fertilizers, pesticides, antibiotics, etc.); and (ii) extensive farming systems based on small farms with mixed crop and livestock production that limit the use of chemical inputs by valuing biological interactions between species but require more time and labor (for crop rotation and care, breeding, harvesting, etc.). Extensive farming systems, such as organic farming systems, offer more favorable conditions for local biodiversity, although they attain lower yields than intensive farming [33, 43, 44].

For these two contrasting and exclusive scenarios, we introduce market equilibrium using a simple method in which we assume a price-increasing supply function and a pricedecreasing demand function for agricultural products at the global level. We also assume that the value of agricultural products is the same for consumers whether farming is intensive or extensive. However, their production costs differ. The differences between the two scenarios are detailed below. 
Similar to Green et al., we assume that any land cultivated using a given farming system has the same yield, with $y_{i}=1$ for intensive farming and $y_{e}<1$ for extensive farming. The biodiversity conservation per unit of land is represented by a decreasing function of yield:

(1) $f(y)=1-y^{\alpha}$,

which may be linear $(\alpha=1)$, convex $(\alpha<1)$, or concave $(\alpha>1)$ (see Figure 1).

This equation normalizes the biodiversity per unit of intensively farmed land to $0(f(1)=$ $0)$ and per unit of uncultivated wildlife spaces to $1(f(0)=1){ }^{1}$

\section{[Insert Figure 1]}

Equation (1) has the advantage of simplicity, although it entails three limitations that were discussed in our introduction: (i) the agricultural yield is independent of the biodiversity level, (ii) the trade-off between biodiversity and yield is independent of the intensification path, and (iii) the biodiversity can be characterized by a single indicator.

\subsection{Agricultural production, land use, and producer surplus}

Production is represented by an inverse supply function that defines price as a function of the quantity supplied by the farm sector, $p=s_{k}(q)$. We assume that this function is linear and defined by $s_{k}(q)=a_{k} q-b$ when farmers use farming system $k$, with $a_{k}>0(k=i$ or $e$ ) (a higher price is needed for producers to supply a higher quantity). ${ }^{2}$ We assume that the price elasticity of supply (the percentage change in production resulting from a $1 \%$ price change) is less than 1, which is consistent with the elasticities from empirical studies for the majority of agricultural products [45]. This price elasticity implies that $b>0 .{ }^{3}$ The inverse supply function is defined on an interval where the marginal costs of production are positive, i.e., $q>$ $b / a_{k}$ (see Figure 2) and production is consistent with the physical limits on land availability, i.e., $q<L y_{k}$. Therefore, the following function is derived:

(2) $\forall q \in\left[b / a_{k}, L y_{k}\right], s_{k}(q)=a_{k} q-b$.

[Insert Figure 2]

For each farming system, land use is equal to production divided by yield as long as a portion of land remains available:

(3) $\forall q \in\left[b / a_{k}, L y_{k}\right], l_{k}(q)=q / y_{k}$.

\footnotetext{
${ }^{1}$ Assuming a positive level of biodiversity on intensively farmed land, such as in Green et al. [11], does not change the results of the model.

${ }^{2}$ This function indicates that the marginal cost of producing the quantity $q$ of the agricultural good with technology $k$ is equal to $s_{k}(q)$. Our model is consistent with the assumption that production is conducted by a continuum of perfectly competitive farmers with different agricultural production costs. Then, the marginal farmer who enters this production system, which is characterized by the highest cost of production, has a cost equal to $s_{k}(q)$. The production level $q$ is obtained when the market price $p$ is equal to $s_{k}(q)$; therefore, all producers receive a positive surplus from their production except the marginal farmer, who produces with a zero surplus.

${ }^{3}$ The price elasticity of supply is $\varepsilon_{s k}=(p / q) \partial q / \partial p=(p / q) /\left(\partial s_{k}(q) / \partial q\right)=\left(a_{k} q-b\right) /\left(a_{k} q\right)$; the value is lower than 1 if and only if $b>0$.
} 
Agricultural producer surplus is the difference between the price received by producers and their cost of production and determined by the area between the price and the inverse supply curve (see Figure 2a):

(4) $\forall q \in\left[b / a_{k}, L y_{k}\right], S U_{k}^{p}(q)=\left(a_{k}^{2} q^{2}-b^{2}\right) /\left(2 a_{k}\right)$.

Finally, we assume that at a given market price, profitability for producers is higher with intensive than with extensive farming. This assumption is consistent with empirical results indicating that organic farming remains a niche market, currently representing $1 \%$ of the world agricultural area [46], and would seldom be competitive with conventional intensive farming without price premiums for organic products (see the meta-analysis in [47], as well as [48], [49] and [50]). It is also consistent with empirical evidence indicating that subsidies and other public policies, as well as public or private research and extension services, favor conventional intensive farming ([48], [51], [52], [53]) which financial, social, health and environmental burdens are only partially addressed ([53], [54], [55]). In our model, this translates into the assumption that production costs are higher with extensive farming than with intensive farming:

(5) $a_{e}>a_{i}$.

Graphically, this inequality implies that the inverse supply curve is higher in the extensive farming scenario than in the intensive farming scenario; therefore, identical production levels may be obtained in the intensive and extensive farming scenarios only if the agricultural price is higher in the extensive scenario.

\subsection{Level of biodiversity according to the farming system}

If land $l_{k}$ is allocated to a crop of type $k$, then the total quantity of biodiversity is given by $l_{k} f\left(y_{k}\right)+\left(L-l_{k}\right) f(0)$; however, because $f(y)=1-y^{\alpha}$, it is written as follows:

(6) $B_{k}\left(l_{k}\right)=L-l_{k} y_{k}^{\alpha}$.

For intensive farming, $y_{i}=1$; therefore, $B_{i}\left(l_{i}\right)=L-l_{i}$. For extensive farming, biodiversity depends on the shape of the relationship between biodiversity and yield as shown in Table 1, where all possible cases are described, including the limit case $\underline{B}_{\mathrm{e}}\left(l_{e}\right)$, where there is no biodiversity in land farmed extensively $(\alpha=0)$, the linear case $B_{e}{ }^{l}\left(l_{e}\right)$, and the limit case $\bar{B}_{\mathrm{e}}$, where farming land extensively does not affect biodiversity $(\alpha \rightarrow+\infty)$.

Table 1. Biodiversity according to the farming system

\begin{tabular}{llll} 
Farming System & $\begin{array}{l}\text { Biodiversity-Yield } \\
\text { relationship: } f(y)=1-y^{\alpha}\end{array}$ & $\begin{array}{l}\text { Biodiversity } \\
B_{k}\left(l_{k}\right)\end{array}$ \\
\hline Intensive $\left(y_{i}=1\right)$ & $f(y)=0$ & & $B_{i}\left(l_{i}\right)=L-l_{i}$ \\
\hline Extensive $\left(y_{e}<1\right)$ & Convex & $\alpha=0$ & $\underline{B}_{\mathrm{e}}\left(l_{e}\right)=L-l_{e}$ \\
& & $\alpha \in(0,1)$ & $B_{e}\left(l_{e}\right) \in\left(L-l_{e}, L-l_{e} y_{e}\right)$ \\
& Linear & $\alpha=1$ & $B_{e} l^{l}\left(l_{e}\right)=L-l_{e} y_{e}$ \\
& & $\alpha \in(1,+\infty)$ & $B_{e}\left(l_{e}\right) \in\left(L-l_{e} y_{e}, L\right)$ \\
& Concave & $\alpha \rightarrow+\infty$ & $\bar{B}_{\mathrm{e}}=L$ \\
\hline
\end{tabular}


We assume that in both possible states of the world, the value of the agricultural product is the same for consumers and does not integrate biodiversity, which is a public good. Inverse demand is modeled classically as a linear decreasing function of quantity:

(7) $d(q)=c-g q$.

Consumer surplus is the difference between the willingness of consumers to pay (that is, the amount of the agricultural good consumers are willing to purchase at a given price) and the price they pay (see Figure $2 b$ ):

(8) $\operatorname{Su}^{\mathrm{c}}(q)=g q^{2} / 2$.

Equilibrium is studied according to the farming system (intensive or extensive) and characterized as follows:

(9) $s_{k}(q)=d(q)$.

Total welfare is the sum of producer surplus, consumer surplus, and the social utility of the conservation of biodiversity, denoted by an increasing function $U$ :

(10) $W_{k}(q)=S U_{k}^{p}(q)+S u^{\mathrm{c}}(q)+U\left(B_{k}\left(l_{k}(q)\right)\right)$.

Throughout the remainder of this article, we use the term "total surplus" to indicate the sum of producer and consumer surplus (this total surplus is different from total welfare because it does not include biodiversity).

Because of our restrictive assumption that production costs and yields are not dependent on the state of biodiversity, the utility derived from biodiversity is independent of the producer surplus in this welfare function. The only environmental impact of agriculture considered in this welfare function is on biodiversity. Additional environmental and health effects caused by the use of chemical fertilizers and pesticides are not considered and may underestimate the negative impacts of intensive farming, which relies more heavily on these inputs.

\section{Rebound effect of agricultural intensification}

\subsection{Graphic analysis of the rebound effect}

Figure 3 illustrates the case of a perfectly inelastic demand (quantity demanded does not respond to prices). Figure 4 illustrates the case of a perfectly elastic demand (there exists a price level for which or below which demand is infinite, while there is no demand for the good at a higher price). Each figure shows the (a) market equilibrium and (b) land use according to the farming choice and the (c) biodiversity conservation according to the farming choice and the yield-biodiversity trade-off.

With a perfectly inelastic demand, and therefore a constant quantity as in Green et al., market equilibrium occurs at price $p_{i}{ }^{*}$ with intensive farming and at the higher price $p_{e}{ }^{*}$ with extensive farming (Figure 3a). To achieve the production level $q_{i}{ }^{*}=q_{e}{ }^{*}$, additional land must be farmed extensively $\left(l_{e}^{*}\right)$ than intensively $\left(l_{i}^{*}\right)$ (Figure $3 \mathrm{~b}$ ). Based on these equilibrium landuse levels, the outcome in terms of biodiversity depends on the trade-off between biodiversity 
and yield. If the relationship between biodiversity and yield is linear, then extensive farming produces the same level of biodiversity as intensive farming $\left(B_{e}{ }^{{ }^{*}}=B_{i}{ }^{*}\right)$ (Figure 3c); if this relationship is convex (between $\underline{B}_{\mathrm{e}}{ }^{*}$ and $B_{e}{ }^{l^{*}}$, depending on the degree of convexity), then extensive farming produces less biodiversity; and if it is concave (between $B_{e}^{l^{*}}$ and $\bar{B}_{\text {e }}$, depending on the degree of concavity), then it produces more biodiversity. These results are identical to those of Green et al. [11] because our framework is similar to theirs when equilibrium consumption is the same for both agricultural systems regardless of their respective profitability.

\section{[Insert Figure 3]}

If the demand is perfectly elastic, then the price level is the same with extensive and intensive farming. The extensive farming equilibrium is characterized by lower production levels (Figure 4a) and higher land use (Figure 4b). Biodiversity is lower with extensive farming if the relationship between biodiversity and yield presents a "high" degree of convexity (between $\underline{B}_{\mathrm{e}}{ }^{*}$ and $\tilde{B}$ ), and it is higher if it presents a "low" degree of convexity or it is linear or concave (between $\tilde{B}$ and $\bar{B}_{\mathrm{e}}$ ).

\section{[Insert Figure 4]}

The results of Green et al. [11] no longer hold if we assume that production results from the market equilibrium. As long as demand is elastic, equilibrium production is higher with intensive farming than with extensive farming. With this rebound effect of intensive farming, the total biodiversity may be higher with extensive farming even when the relationship between biodiversity and yield is convex.

We complete the analysis by considering the welfare differences between the two farming scenarios. If the demand is perfectly inelastic (Figure 3), then extensive farming provides a greater benefit to producers than intensive farming, although it is detrimental to consumers and the total surplus. These changes in surplus correspond to the established results in the literature in which a productivity loss is detrimental to the consumer surplus and total surplus, but may increase the producer surplus if it is accompanied by a price increase because of an inelastic demand [45]. If the demand is perfectly elastic (Figure 4), then the producers have a lower surplus with extensive farming (rather than intensive) and both farming systems yield a zero consumer surplus. In both cases, when extensive farming yields a higher biodiversity level, its social utility alleviates or even cancels out the loss of producer and consumer surpluses, whereas in the opposite case, the lower biodiversity associated with extensive farming worsens the negative welfare impact of extensive farming.

\subsection{Analytical effect of farming systems on biodiversity}

The previous graphic results have been obtained for perfectly elastic or perfectly inelastic demand. We now extend the results analytically to a case in which demand is imperfectly elastic (the slope of the inverse of the linear demand curve $c$ is positive and finite). Based on the definition of supply and demand in equations (1) and (7), the equilibrium equation (9) yields the equilibrium quantity $q_{k}{ }^{*}$. The equilibrium price $p_{k}{ }^{*}$ is then defined equivalently by $s_{k}\left(q_{k}{ }^{*}\right)$ or $d\left(q_{k}{ }^{*}\right)$. The equilibrium farmed land, producer surplus, consumer surplus, and biodiversity level are obtained from equations (3), (4), (8), and (6), respectively. The equilibrium values are given in Table 2, and Proposition 1 is inferred from these values. 
Table 2. Equilibrium values of the model variables

$\begin{array}{ll}\text { Price } & p_{k}{ }^{*}=\left(a_{k} c-b g\right) /\left(a_{k}+g\right) \\ \text { Agricultural production } & q_{k}{ }^{*}=(b+c) /\left(a_{k}+g\right) \\ \text { Farmed land } & l_{k}{ }^{*}=(b+c) /\left(\left(a_{k}+g\right) y_{k}\right) \\ \text { Producer surplus } & S U^{p}{ }^{*}=a_{k}(b+c)^{2} /\left(2\left(a_{k}+g\right)^{2}\right)-b^{2} /\left(2 a_{k}\right) \\ \text { Consumer surplus } & S U^{c}{ }^{*}=g(b+c)^{2} /\left(2\left(a_{k}+g\right)^{2}\right) \\ \text { Biodiversity } & B_{k}{ }^{*}=1-(b+c) y_{k}{ }^{\alpha-1} /\left(a_{k}+g\right)\end{array}$

Note: $a_{i}$ and $a_{e}$ are the slopes of the intensive and extensive inverse supply curves, respectively, with $a_{e}>a_{i} ; b$ is the opposite of the intercept of the linear supply curve; $c$ and $g$ are the intercept and the slope of the inverse demand curve, respectively; $y_{i}=1$ is the yield of intensive farming; $y_{e}<1$ is the yield of extensive farming; and $\alpha$ is the parameter that characterizes the degree of concavity or convexity of the relationship between biodiversity and yield. All of these parameters are positive. A necessary and sufficient condition for equilibrium is a positive equilibrium price, $a_{k} c>b g$.

Proposition 1. Comparison of equilibrium and welfare under extensive and intensive farming.

If the land availability is not exhausted, then the following holds under extensive farming:

- the price level is higher and the levels of production, consumer surplus, and total (consumer and producer) surplus are smaller;

- land use, biodiversity, and producer surplus may be higher or lower:

- Land use is higher if and only if $g+a_{i}>\left(g+a_{e}\right) y_{e}$;

- The biodiversity levels is higher if and only if $g+a_{e}>\left(g+a_{i}\right) y_{e}^{\alpha-1}$ (or equivalently, $\alpha>\tilde{\alpha}$, with $\left.\tilde{\alpha}=1-\ln \left(\left(a_{e}+g\right) /\left(a_{i}+g\right)\right) / \ln \left(1 / y_{e}\right)\right)$;

- Producer surplus is higher if and only if $(b+c)^{2}\left[a_{i} /\left(a_{i}+g\right)^{2}-a_{e} /\left(a_{e}+g\right)^{2}\right]>b^{2}\left(a_{e}\right.$ $\left.-a_{i}\right) /\left(a_{e} a_{i}\right)$.

This proposition extends the graphic evidence provided above on the conditions under which the basic result of the initial LSS framework holds. Proposition 1 shows that as long as extensive farming is more costly than intensive farming and as long as demand reacts to prices, then the price will be higher and the agricultural production (and consumption) will be lower than that under intensive farming. This market reaction reduces the negative impact of extensive farming on land use and biodiversity loss, and it extends the range of situations in which extensive farming performs better than intensive farming in terms of biodiversity conservation.

Based on this proposition, extensive farming may use less land than intensive farming under certain parameter values, which would result in a higher biodiversity level regardless of the shape of the relationship between biodiversity and yield. ${ }^{4}$ The most expected scenario, however, is that farmed land will be higher with extensive farming, and according to the

\footnotetext{
${ }^{4}$ Because $y_{e} \in(0,1)$ and $\alpha>0$, we have $y_{e}{ }^{\alpha}<1$. Land use decreases when $\left(g+a_{e}\right) y_{e}>g+a_{i}$, which implies $(g$ $\left.+a_{e}\right) y_{e}>\left(g+a_{i}\right) y_{e}^{\alpha}$, the condition under which biodiversity increases.
} 
above proposition, occurs under the following conditions: demand does not respond excessively to price ( $g$ is high enough), the yield of extensive farming $\left(y_{e}\right)$ is sufficiently small compared with the yield of intensive farming $\left(y_{i}=1\right)$, and/or the unit production costs are not excessively higher under extensive farming than with intensive farming ( $a_{e}$ not much higher than $a_{i}$ ).

When farmed land is higher under extensive farming, the biodiversity level is also higher when the relationship between biodiversity and yield is linear or concave $(\alpha \geq 1){ }^{5}$ When this relationship is convex $(\alpha<1)$, the outcome in terms of biodiversity depends on the relative values of parameter $\alpha$, the yield of extensive farming $\left(y_{e}\right)$, the inverse demand slope $(g)$, and the extensive and intensive inverse supply slopes $\left(a_{i}\right.$ and $\left.a_{e}\right)$. It is more likely that biodiversity will be higher under extensive farming if the demand quantity responds to prices (low $g$ ), the extensive supply responds less to price compared with the intensive supply $\left(a_{e}\right.$ sufficiently higher than $a_{i}$ ), and the relationship between biodiversity and yield has a low degree of convexity ( $\alpha$ close to 1$)^{6}{ }^{6}$

In all cases, extensive farming is detrimental for consumers, who reduce their purchases because of higher prices, and it has a negative impact on the aggregate producer and consumer surplus because of the higher production costs under extensive farming. However, as is usually the case with this type of model, there is no intuitive interpretation of the cases in which the producer surplus is higher or lower. ${ }^{7}$

\subsection{Numerical illustration with a low elasticity of demand}

The rebound effect (higher market size in the equilibrium with intensive farming) hinges on the condition that the demand for agricultural goods increases when the prices decrease. However, available empirical evidence suggests that the price elasticities of demand for agricultural goods are low, at least in the short run (see, e.g., USDA ERS [56] and FAPRI [57]). To assess the extent to which the integration of market equilibrium empirically affects the result of the initial LSS framework within a context of low change in demand with regards to price, we have run numerical simulations with plausible values of supply and demand elasticities. In these simulations, we consider an unfavorable biodiversity case under extensive farming by assuming a low elasticity of demand, a convex relation between biodiversity and yield and a higher land use value.

We rely on the estimates of agricultural supply and demand elasticities provided by Roberts and Schlenker [58], who have aggregated four major crops (corn, wheat, rice and soybean) that together account for three quarters of the caloric content of the global food production. Our simulations are run with the lowest and highest estimations of their demand and supply elasticities. Thus, with intensive farming, the supply elasticity is $\varepsilon_{s i} \in\{0.09,0.14\}$ and the demand elasticity is $\varepsilon_{d} \in\{-0.07,-0.03\}$. We consider the case where extensive

\footnotetext{
${ }^{5}$ Because $a_{e}>a_{i}$ and $y_{e}<1$, we have $\left.\ln \left(\left(a_{e}+g\right) /\left(a_{i}+g\right)\right) / \ln \left(1 / y_{e}\right)\right)>0$, and therefore, $\tilde{\alpha}<1$.

${ }^{6}$ In the case where the relation between biodiversity and yield is convex, because $y_{e} \in(0,1)$ and $\alpha \in[0,1)$, we have $y_{e}^{\alpha-1}>1$, with $y_{e}^{\alpha-1} \rightarrow 1$ when $\alpha \rightarrow 1$ and $y_{e}^{\alpha-1}=1 / y_{e}$ when $\alpha=0$.

${ }^{7}$ Analogous to Karagiannis and Furtan [44], who consider an infinitesimal variation in the slope of the supply curve, it is possible to interpret only a necessary condition for an increase in producer surplus. This necessary condition is that the section between square brackets of the left-hand term in the inequality presented in Proposition 1 must be positive, which is the case if and only if $a_{i} a_{e}>g^{2}$ (the product of the two slopes of the inverse supply is higher than the square of the inverse demand slope).
} 
farming is characterized by a $10 \%$ lower yield than intensive farming. We numerically assume that the relationship between biodiversity and yield is convex $(\alpha<1)$, in which case biodiversity conservation on extensively farmed land must be less than $10 \%$ of the biodiversity of unfarmed land $\left(0 \leq f\left(y_{e}\right)<10 \%\right)$. In the simulations, these values vary between $1 \%$ and $9 \%$ and different values are assigned to the extensive supply slope, which is consistent with the assumption that land use is higher with extensive farming (see note to Figure 5).

In these simulations, biodiversity is lower with extensive farming rather than with intensive farming by $1 \%$ on average, and the standard deviation is $6 \%$ (Figure $5 \mathrm{a}$ ). Thus, even in the unfavorable case considered here, the level of biodiversity is higher with extensive farming for an important set of parameter values. When we additionally assume that the degree of convexity of the biodiversity-yield relationship is very high, with extensively farmed land conserving only $2 \%$ of the biodiversity that would prevail on uncultivated land $(\alpha$ $\approx 0.19$ ), then extensive farming leads to a $7 \%$ lower biodiversity on average than intensive farming (with a standard deviation of 3\%) (Figure 5b). If the biodiversity-yield relationship convexity is lowered so that the biodiversity per land unit is four-fold higher, or $8 \%$ of the biodiversity level of uncultivated land $\left(f\left(y_{e}\right)=0.08, \alpha \approx 0.79\right)$, then extensive farming practices increase biodiversity by $5 \%$ on average (with a standard deviation of $3 \%$ ) (Figure $5 \mathrm{c})$. These simulations illustrate that the LSS results may be reverted when market effects are considered, even under scenarios with a low elasticity of demand for agricultural products.

[Insert Figure 5]

\section{Rebound effect with land-use zoning and food-feed-biofuel production}

We now consider two extensions of our model to integrate two dimensions of the debates surrounding the assumption of an exogenous production target in the initial LSS framework. One extension pertains to the effect of zoning certain lands for conservation on our results, whereas the other pertains to the possibility of producing different goods from the plant product that do not all contribute equally to food security. These extensions enable us to clarify the effect of agricultural extensification in the two examined cases.

\subsection{Agricultural pressure on land zoned for conservation according to the farming systems}

We have considered that agricultural land use is determined by the equilibrium of the agricultural market. We now consider the hypothetical effect of implementing an "active" land sparing mechanism to overcome the rebound effect of "passive" land sparing [29]. We consider that a portion of land is zoned for agriculture and another for conservation to conserve a minimum level of biodiversity $B_{c}$.

The effect of land-use zoning is represented in Figure 6. For clarity, we have concentrated on the case of a linear relationship between biodiversity and yield and plotted the equilibria with intensive and extensive farming separately. Since there is greater biodiversity on land farmed extensively than intensively, the conservation of a minimum biodiversity level imposes a larger zone for agriculture and a smaller zone for conservation 
when farming is extensive rather than intensive. With exogenous yield levels, zoning land for agriculture is then equivalent to introducing a production quota $q_{\mathrm{c}}$, which is identical for both production systems under the assumption of a linear relationship between biodiversity and yield adopted in the figure.

[Insert Figure 6]

Because land-use zoning limits agricultural expansion, incentives to encroach on land zoned for conservation occur. In equilibrium, the agricultural price under both farming systems is higher than the marginal cost of production, and farmers who find it profitable to encroach conservation zones are those with a cost of production ranging from $m c_{i c}$ (the marginal cost of production in equilibrium) to $p_{i c}$ (the equilibrium market price) in the case of intensive farming, and a marginal cost of production ranging from $m c_{e c}$ to $p_{e c}$ in the case of extensive farming. As shown on Figure 6, the incentive to encroach on land zoned for conservation is higher for intensive farming than for extensive farming.

This graphic analysis can be generalized by analytically determining the wedge between the market price and the marginal production cost resulting from the implementation of the conservation zone under each production system. From our equilibrium model, this price-cost wedge is calculated as follows:

(11) $p_{k c}-m c_{k c}=b+c-\left(a_{k}+g\right)\left(1-B_{c}\right) y_{k}{ }^{1-\alpha}, k \in\{i, e\}^{8}$

where $p_{k c}$ and $m c_{k c}$ are the price and the marginal cost of production when the equilibrium is constrained by the protection of a minimum biodiversity level $B_{c}$, respectively.

When biodiversity protection constrains agricultural expansion, the encroachment of agriculture on land zoned for conservation is profitable. The incentive to encroach on conservation zones is higher with intensive rather than extensive farming under the condition $p_{i c}-m c_{i c}>p_{e c}-m c_{e c}$, which is equivalent to $\left(a_{e}+g\right) y_{e}{ }^{1-\alpha}>a_{i}+g$ as summarized in Proposition 2.

\section{Proposition 2. Incentives to encroach on land zoned for conservation.}

Zoning land for agriculture and conservation to ensure a minimum level of biodiversity introduces a wedge between the equilibrium price and the marginal production costs within the agricultural market. This wedge creates an incentive for potential producers whose marginal production costs are smaller than the equilibrium price to encroach on land zoned for conservation. The price to marginal cost wedge and the incentive to encroach are higher with intensive than extensive farming if and only if $\left(a_{e}+g\right) y_{e}{ }^{1-\alpha}>a_{i}+g$. Because $a_{e}>a_{i}$ (equation 5), this condition holds as long as the relationship between biodiversity and yield is linear, concave $(\alpha \geq 1)$ or has a sufficiently low degree of convexity $(\alpha<1)$.

This proposition notes the difficulties of land-use zoning to implement "active" land sparing because farmers have an incentive to encroach on land zoned for conservation (see

\footnotetext{
${ }^{8}$ A minimum level of biodiversity $B_{c}$ introduces a cap on land use $l_{k c}$ with farming system $k \in\{i, e\}$. From equation (6), this cap is defined by $l_{k c}=\left(1-B_{c}\right) y_{k}^{-\alpha}$; from equation (3), it results in a production cap $q_{k c}=\left(1-B_{c}\right) y_{k}{ }^{1-\alpha}$. The price equilibrium is at the intersection of the production cap and the inverse demand curve (7), $p_{k c}=c-g q_{k c}$, whereas the marginal cost of production is at the intersection of the production cap and the inverse supply curve (2), $m c_{k c}=a_{k} q_{k c}-b$. Therefore, the price-cost difference is $p_{k c}-m c_{k c}=b+c-\left(a_{k}+g\right)$ $q_{k c}$; based on the expression of $q_{k c}$, this difference yields equation (11).
} 
also Phelps et al. [59]). The incentive to encroach is higher when farming is intensive rather than extensive for many of the parameter values in our model.

\subsection{Food, feed and biofuel goods}

Although our model should not be used to address food security issues beyond food production, it may provide insights into such issues by incorporating an extension with different possible goods produced from the same plant product. This multi-good model can be used to analyze the effect of intensive or extensive production systems on market equilibria and determine the extent to which these systems may actually favor specific uses that have the potential to impact food security.

A unique plant product is considered here, and we distinguish three possible goods produced from this plant product: plant-based food, denoted by $F$; animal feed for the production of meat, milk, and eggs (or simply "feed"), denoted by $f$; and biofuels, denoted by $b$. For simplification, we assume that demands for these three products are independent. They are modeled as follows:

(12) $d^{k}(q)=c_{k}-g_{k} q, k=F, f$ or $b$.

The total inverse demand function is then as follows:

(13) $c=\left(\sum_{k} c_{k} / g_{k}\right) /\left(\sum_{k} 1 / g_{k}\right) ; g=1 /\left(\sum_{k} 1 / g_{k}\right), k=F, f$ or $b{ }^{9}$

The former framework applies, with demand parameters $c$ and $g$ now defined by (12) as functions of the parameters of the three inverse demand functions.

The literature usually does not distinguish among the price elasticities of plant-based food, feed, or biofuel uses of plant products, because many plant products, such as cereals and oilseeds, are suitable for all three uses, which increases the difficulty of estimating their individual elasticities. We assume that the feed demand (demand for plant products used for animal feed) is more price elastic than the plant-based food demand. Indeed, the demand elasticities for animal-based products, such as milk or meat, are higher than the demand elasticities for cereal foodstuffs, such as rice or bread [56]. Conversely, we assume that biofuel is price inelastic because of current policies (such as in the United States, Europe, and Brazil) in which biofuels must be blended into fossil fuel [60]. Given such policies, an increase in the agricultural price contributes to increase slightly fuel prices and therefore decrease slightly the demand for fuels, causing a small decrease in the quantity of the plant product used for biofuel production [61]. Therefore, the inverse demand for biofuels has a higher slope than the inverse demand for food, which has a higher slope than the demand for feed:

(14) $g_{b}>g_{F}>g_{f}$.

As previously analyzed, the equilibrium price is higher with extensive than intensive farming. Based on Assumption (13), this price increase primarily leads to a decrease in the production of feed, which has a more elastic demand, and has less of an effect on plant-based food. In addition, biofuel demand is quasi-identical under both farming systems as illustrated in Figure 7.

\footnotetext{
${ }^{9}$ For each product, the demand function is $D^{k}(p)=c_{k} / g_{k}-p / g_{k}$. Therefore, the total demand is $D(p)=\left(\sum_{k} c_{k} /\right.$ $\left.g_{k}\right)-\left(\sum_{k} l / g_{k}\right) p$, from which we deduce the expression of the total inverse demand in (12).
} 


\section{Insert Figure 7}

This analysis allows us to discuss the argument developed by Angelsen [62] that "higher yield can reduce the food share, as food demand is typically more price inelastic than demand for nonfood commodities." Our analysis shows that as long as our assumptions on price elasticities for the different agricultural goods are plausible, Angelsen's result holds in our context in terms of feed versus plant-based food consumption but not in terms of biofuel versus total food consumption. In our model, extensive farming may alleviate pressures on biodiversity by increasing the agricultural price, which is primarily a detriment to feed production and has less of an effect on plant-based food production, and even less on biofuel production.

It should be emphasized that mandatory blending policies reduces the effect of changes in farming systems on biofuel production. The scientific debate on the environmental effects of biofuels remains largely centered on greenhouse gas emissions, which may decrease or increase depending on indirect changes in land use. However, the effect of biofuels on biodiversity, which is less frequently studied, is indubitably negative (see Krausmann et al. [63]), and based on the current policies mandating their increased use, neither an intensive nor an extensive farming system can be expected to significantly mitigate this negative impact.

In our model, feed production is significantly smaller under extensive rather than intensive farming, and this difference could have a positive impact on biodiversity by reducing the higher pressure exerted by the demand for animal-based food products (and, thus, for feed to produce them) than that exerted by the demand for plant-based food products. Indeed, approximately three calories (or proteins) of plant products that could directly feed humans (e.g., cereals or oilseeds) are currently used to feed animals to produce one calorie (or protein) of edible animal products (meat, milk, and eggs) [20 ${ }^{10}$. Moreover, this 3:1 ratio tends to increase over time because increases in the demand for animal-based food products increase the incentives to convert grazing pastures or forests into feed crops, which are often monocultures of cereals and oilseeds with a higher production of feed per unit of land.

A reduction in animal feed production would be detrimental in terms of consumer surplus, although it may not have as great of an effect on food security because human beings don't need to eat animal-based food in large quantity [64]. In this respect, it should be noted that the per capita consumption of animal-based food is by far the highest among wealthy countries, as well as the conversion of plant food products into animal feed products. ${ }^{11} \mathrm{~A}$ preference for extensive farming would therefore have a stronger impact on consumers in wealthy countries through increases in the price of animal-based food, which they tend to overconsume to the detriment of their health (cardiovascular and other diseases). Therefore, public policies encouraging extensive farming could complement other policies aimed at influencing consumption patterns to decrease the overconsumption of animal-based food [20].

The higher prices under extensive farming could be detrimental to food security by reducing food production and would impact consumers in poor countries, especially poor urban consumers who rely on imports, which occurred during the 2007-2008 international food price hike. However, three factors that lie beyond the scope of our model may balance

\footnotetext{
${ }^{10}$ This ratio is a world average and excludes biomass that is not edible for humans but edible for animals, such as pastures, fodder crops, and crop residues.

${ }^{11}$ In poor countries, there is a significantly higher use of non-food biomass for feed (such as bush or crop / food residues) because arable land is mainly cultivated for food. Milk and meat yields are lower per animal, although these animals provide other key services (traction; soil fertilization, fuel or building material with animal feces) [20].
} 
this effect. First, this increase in agricultural prices could benefit the hundreds of millions of small agricultural producers concentrated in Asia, Africa, and Latin America, who are among the poorest consumers in the world and account for the main share of farmers [65]. Second, the additional biodiversity resulting from a scenario with extensive farming could have beneficial effects on the provision of ecosystem services associated with the health and welfare of consumers, notably the poorest consumers [66], with these services including biological plant, animal, and human disease control (instead of pesticides or antibiotics), water purification, and nutrient recycling. Third, additional biodiversity resulting from a scenario with extensive farming may have positive effects in the medium and long run on yields and their resilience by improving soil fertility, local climate conditions, and/or pollination [67].

\section{Conclusions}

The effect on biodiversity of conventional agricultural intensification has been highly disputed in the academic literature, especially in the field of ecology, since the publication in 2005 of Green et al.'s LSS article in favour of the "land sparing" option where biodiversity and agriculture production are segregated spatially in order to maximize both. Here, we propose an analytical framework that compares an "intensive" agriculture (no biodiversity) and an "extensive" agriculture (more biodiversity-friendly) at market equilibrium and not at a specific production target level as in the initial LSS model. We show that the integration of market effects extends the set of scenarios in which extensive farming is more favorable to biodiversity than intensive farming. As long as demand is responsive to prices and extensive farming is more costly than intensive farming, there is indeed a rebound effect of farming intensification. i.e. a higher equilibrium production. This rebound effect limits the extent to which intensive farming can conserve land from agricultural use. As a result, intensive farming may be more detrimental to biodiversity than extensive farming, even when biodiversity is more affected by the conversion of land to agriculture than by the degree of agricultural intensification. In other words, compared with the case in the initial LSS framework, intensive farming may not perform better than extensive farming in terms of biodiversity conservation even if the relationship between biodiversity and yield is convex. The outcome of farming on biodiversity is actually better with an intensive rather than extensive production system only if the degree of this convexity is very high. Using numerical simulations, we illustrate that this result holds true even when the price elasticity of agricultural demand is low, which is supported by the available empirical evidence. We also note that consumer surplus and the aggregate of consumer and producer surpluses are lower with extensive farming; however, the effect on producer surplus is indeterminate. Therefore, when extensive farming is optimal for biodiversity, a trade-off occurs between biodiversity conservation and consumer and producer surpluses.

We also discuss the extent to which conservation zones affect the rebound effect of intensive farming. In our model, conservation zones have a similar effect as a production quota. Therefore, they introduce a difference between the agricultural consumer price and the marginal production cost. As a result, farmers have an incentive to encroach on these

conservation zones. Because of the rebound effect of market intensification, this incentive to encroach is higher when farming is intensive rather than extensive for a large set of situations; thus, farming intensification increases the difficulty of implementing "active" land sparing through land-use zoning. Finally, we argue that the smaller production levels in the scenario 
with extensive rather than intensive farming would primarily affect feed production. We also argue that the loss of food security caused by an increase in food prices would be mitigated by several effects that are not integrated in our modeling framework, including improved living conditions for poor farmers, the provision of enhanced ecosystem services, and the positive long-run effect of biodiversity on yields and their resilience to shocks. We also note that biofuel production is not expected to be significantly affected by changes in production systems as long as public policies mandate biofuel blending into fossil fuels.

This research provides a formal comparison of how intensive and extensive production systems affect biodiversity at market equilibrium rather than at a target production level. However, our model does not address the other dimension of the debates and discussions pertaining to the initial LSS framework and its oversimplified assumptions regarding the relationship between biodiversity and yield. Our model may overestimate the set of scenarios in which intensive farming produces a better outcome than extensive farming by ignoring the negative impacts caused by intensive farming other than the loss of biodiversity. In addition, our model ignores the positive and dynamic effects of yield gains that occur through enhanced biodiversity, especially under an agroecological intensification path. The analysis of such effects in a dynamic bio-economic framework will be the subject of future research.

Our analysis could also be extended to distinguish among different countries according to their level of development and contribution to the international trade of agricultural commodities. Such an analysis would enable us to determine in greater detail the effects of contrasted farming systems on different agricultural productions and on the three components of welfare (producer surplus, consumer surplus, and biodiversity) for each type of country. It would also be interesting to consider surpluses along the agro-food chains. This could be accomplished by distinguishing between farmers, for which welfare effects are indeterminate in our model, and industrial input suppliers (chemical fertilizers, pesticides and fossil energy), which would have smaller surpluses with extensive farming.

Acknowledgments. We wish to thank two anonymous referees as well as Guy Meunier for helpful comments. Financial support was granted by the French National Research Agency, project ANR-11-ALID-002-01 'Offrir et Consommer une Alimentation Durable'. 


\section{References}

1. Butchart, S.H., Walpole, M., Collen, B., Van Strien, A., Scharlemann, J.P., Almond, R.E., et al. (2010). Global biodiversity: indicators of recent declines. Science, 328(5982), 1164-1168.

2. Barnosky, A.D., Matzke, N., Tomiya, S., Wogan, G.O., Swartz, B., Quental, T.B., et al. (2011). Has the Earth's sixth mass extinction already arrived? Nature, 471(7336), 51-57.

3. Foley, J.A., Ramankutty, N., Brauman, K.A., Cassidy, E.S., Gerber, J.S., Johnston, M., et al. (2011). Solutions for a cultivated planet. Nature, 478(7369), 337-342.

4. Pereira, H.M., Navarro, L.M., Martins, I.S. (2012). Global biodiversity change: the bad, the good, and the unknown. Annual Review of Environment and Resources, $37(1), 25-50$.

5. Newbold, T., Hudson, L.N., Hill, S.L., Contu, S., Lysenko, I., Senior, R.A., et al. (2015). Global effects of land use on local terrestrial biodiversity. Nature, 520(7545), 45-50.

6. Donald, P.F., Gree, R.E., Heath, M.F. (2001). Agricultural intensification and the collapse of Europe's farmland bird populations. Proceedings of the Royal Society of London B: Biological Sciences, 268(1462), 25-29.

7. Alexandratos, N., Bruinsma, J. (2012). World agriculture towards 2030/2050: the 2012 revision. ESA Working Paper 12-03, Rome: FAO.

8. Fritz, S., See, L., van der Velde, M., Nalepa, R.A., Perger, C., Schill, C., et al. (2013). Downgrading recent estimates of land available for biofuel production. Environmental Science and Technology, 47(3), 1688-1694.

9. Cardinale, B.J., Duffy, J.E., Gonzalez, A., Hooper, D.U., Perrings, C., Venail, P., et al. (2012). Biodiversity loss and its impact on humanity. Nature, 486(7401), 59-67.

10. Isbell, F., Tilman, D., Polasky, S., Loreau, M. (2015). The biodiversity-dependent ecosystem service debt. Ecology Letters, 18(2), 119-134.

11. Green, R.E., Cornell, S.J., Scharlemann, J.P., Balmford, A. (2005). Farming and the fate of wild nature. Science, 307(5709), 550-555.

12. Borlaug, N.E. (1987). Making institutions work: a scientists viewpoint. College Station, TX: Texas A \& M University Press.

13. Goklany, I.M., Sprague, M.W. (1992). Sustaining development and biodiversity: productivity, efficiency and conservation. Washington DC: Cato Institute.

14. Waggoner, P.E. (1996). How much land can ten billion people spare for nature? Daedalus, 125, 73-93.

15. Avery, D.T. (1997). Saving nature's legacy through better farming. Issues in Science and Technology, 14(1), 59.

16. Borlaug, N.E. (2002). Feeding a world of 10 billion people: the miracle ahead. In Vitro Cellular and Developmental Biology-Plant, 38(2), 221-228.

17. Phalan, B., Onial, M., Balmford, A., Green, R.E. (2011). Reconciling food production and biodiversity conservation: land sharing and land sparing compared. Science, 333(6047), 1289-1291. 
18. Fischer, J., Abson, D.J.. Butsic, V., Chappell, M.J., Ekroos, J., Hanspach, J., et al. (2014). Land sparing versus land sharing: moving forward. Conservation Letters, 7(3), 149-157.

19. Fischer, J., Batary, P., Bawa, K.S., Brussaard, L., Chappell, M.J., Clough, Y., et al. (2011). Conservation: limits of land sparing. Science, 334(6056), 593.

20. Paillard, S., Tréyer, S., Dorin, B., editors (2014). Agrimonde - scenarios and challenges for feeding the world in 2050. The Netherlands: Springer Verlag.

21. Tscharntke, T., Clough, Y., Wanger, T.C., Jackson, L., Motzke, I., Perfecto, I., et al. (2012). Global food security, biodiversity conservation and the future of agricultural intensification. Biological Conservation, 151(1), 53-59.

22. Matson, P.A., Vitousek, P.M. (2006). Agricultural intensification: will land spared from farming be land spared for nature? Conservation Biology, 20(3), 709-710.

23. Vandermeer, J., Perfecto, I. (2007). The agricultural matrix and a future paradigm for conservation. Conservation Biology, 21(1), 274-277.

24. Perfecto, I., Vandermeer, J. (2010). The agroecological matrix as alternative to the land-sparing/agriculture intensification model. Proceedings of the National Academy of Sciences of the United States of America, 107(13), 5786-5791.

25. Lambin, E.F., Meyfroidt, P. (2011). Global land use change, economic globalization, and the looming land scarcity. Proceedings of the National Academy of Sciences of the United States of America, 108(9), 3465-3472.

26. Ewers, R.M., Scharlemann, J.P.W., Balmford, A., Green, R.E. (2009). Do increases in agricultural yield spare land for nature? Global Change Biology, 15(7), 1716-1726.

27. Phalan, B., Balmford, A., Green, R.E., Scharlemann, J.P.W. (2011). Minimizing the harm to biodiversity of producing more food globally. Food Policy, 36, S62-S71.

28. Balmford, A., Green, R., Phalan, B. (2012). What conservationists need to know about farming. Proceedings of the Royal Society. Series B: Biological Sciences, 279(1739), 2714-2724.

29. Phalan, B., Green, R.E., Dicks, L.V., Dotta, G., Feniuk, C., Lamb, A., et al. (2016). How can higher-yield farming help to spare nature? Science, 351(6272), 450-451.

30. Deguines, N., Jono, C., Baude, M., Henry, M., Julliard, R., Fontaine, C. (2014). Large-scale trade-off between agricultural intensification and crop pollination services. Frontiers in Ecology and the Environment, 12(4), 212-217.

31. Garibaldi, L.A., Aizen, M.A., Klein, A.M., Cunningham, S.A., Harder, L.D. (2011). Global growth and stability of agricultural yield decrease with pollinator dependence. Proceedings of the National Academy of Sciences of the United States of America, 108(14), 5909-5914.

32. Garibaldi, L.A., Carvalheiro, L.G., Vaissière, B.E., Gemmill-Herren, B., Hipólito, J., Freitas, B.M., et al. (2016). Mutually beneficial pollinator diversity and crop yield outcomes in small and large farms. Science, 351(6271), 388-391.

33. Reganold, J.P., Wachter, J.M. (2016). Organic agriculture in the twenty-first century. Nature Plants, 2(2), 15221.

34. Clough, Y., Barkmann, J., Juhrbandt, J., Kessler, M., Wanger, T.C., Anshary, A., et al. (2011). Combining high biodiversity with high yields in tropical agroforests. 
Proceedings of the National Academy of Sciences of the United States of America, 108(20), 8311-8316.

35. Altieri, M.A. (1999). The ecological role of biodiversity in agroecosystems. Agriculture, Ecosystems and Environment, 74(1-3), 19-31.

36. Bommarco, R., Kleijn, D., Potts, S.G. (2013). Ecological intensification: harnessing ecosystem services for food security. Trends in Ecology and Evolution, 28(4), 230238.

37. Griffon, M. (2013). Qu'est-ce que l'agriculture écologiquement intensive? Matière à débattre et décider. Versailles: Quae.

38. Foley, J.A., DeFries, R., Asner, G.P., Barford, C., Bonan, G., Carpenter, S.R., et al. (2005). Global consequences of land use. Science, 309(5734), 570-574.

39. Hart, R., Brady, M., Olsson, O. (2014). Joint production of food and wildlife: uniform measures or nature oases? Environmental and Resource Economics, 59(2), 187-205.

40. Hertel, T.W., Ramankutty, N., Baldos, U.L. (2014). Global market integration increases likelihood that a future African Green revolution could increase crop land use and $\mathrm{CO} 2$ emissions. Proceedings of the National Academy of Sciences of the United States of America, 111(38), 13799-13804.

41. Martinet, V. (2014). The economics of the food versus biodiversity debate. Paper prepared for presentation at the EAAE 2014 Congress, Agri-Food and Rural Innovations for healthier societies, Ljubljana, Slovenia, August 26-29.

42. Meunier, G. (2014). Land-sparing vs land-sharing with incomplete policies. INRA ALISS Working Paper 2014-05.

43. Seufert, V., Ramankutty, N., Foley, J.A. (2012). Comparing the yields of organic and conventional agriculture. Nature, 485(7397), 229-232.

44. Ponisio, L.C., M'Gonigle, L.K., Mace, K.C., Palomino, J., de Valpine, P., Kremen, C. (2015). Diversification practices reduce organic to conventional yield gap.

Proceedings of the Royal Society of London B: Biological Sciences, 282(1799), 20141396.

45. Karagiannis, G., Furtan, W.H. (2002). The effects of supply shifts on producers' surplus: the case of inelastic linear supply curves. Agricultural Economics Review, 3, $5-11$.

46. Willer, H., Lernoud, J. (2016). The world of organic agriculture: statistics and emerging trends 2016. Research Institute of Organic Agriculture (FiBL), Frick, and IFOAM - Organics International

47. Crowder, D.W., Reganold, J.P. (2015). Financial competitiveness of organic agriculture on a global scale. Proceedings of the National Academy of Sciences of the United States of America, 112(24), 7611-7616.

48. Nemes, N. (2009). Comparative analysis of organic and non-organic farming systems : A critical assessment of farm profitability. Natural Resources Management and Environment Department, FAO, Rome.

49. Kuminoff, N.V., Wossink, A., (2010). Why isn't more US farmland organic? Journal of Agricultural Economics, 61(2), 240-258. 
50. McBride, W.D., Greene, C., Foreman, L., and Ali, M. (2015). The profit potential of certified organic field crop production. U.S. Department of Agriculture, Economic Research Service, ERR-188, July.

51. Vanloqueren, G., Baret, P.V. (2008). Why are ecological, low-input, multi-resistant wheat cultivars slow to develop commercially? A Belgian agricultural 'lock-in' case study. Ecological Economics, 66(2-3), 436 - 446.

52. Vanloqueren, G., Baret, P.V. (2009). How agricultural research systems shape a technological regime that develops genetic engineering but locks out agroecological innovations. Research Policy, 38(6), 971-983.

53. Dorin, B., Jullien, T., editors (2004). Agricultural incentives in India. Past trends and prospective paths towards sustainable development. New Delhi: Manohar.

54. Bourguet, D., Guillemaud, T. (2016). The hidden and external costs of pesticide use. Sustainable Agriculture Reviews, 19, 35-120.

55. Sutton, M. A, Howard, C.M., Erisman, J.W., Billen, G., Bleeker, A., Grennfelt, P, et al., editors (2011). The European nitrogen assessment. Cambridge: Cambridge University Press.

56. USDA ERS (United States Department of Agriculture, Economic Research Service). (2015). Commodity and food elasticities. http://www.ers.usda.gov/dataproducts/commodity-and-food-elasticities/about.aspx. Accessed 3 August 2015.

57. FAPRI (Food and Agricultural Policy Research Institute). (2015). FAPRI elasticity database. http://www.fapri.iastate.edu/tools/elasticity.aspx. Accessed 3 August 2015.

58. Roberts, M.J., Schlenker, W. (2013). Identifying supply and demand elasticities of agricultural commodities: implications for the US ethanol mandate. American Economic Review, 103(6), 2265-2295.

59. Phelps, J., Carrasco, L.R., Webb, E.L., Koh, L.P., Pascual, U. (2013). Agricultural intensification escalates future conservation costs. Proceedings of the National Academy of Sciences of the United States of America, 110(19), 7601-7606.

60. HLPE (High Level Panel of Experts). (2013). Biofuels and food security. A report by the High Level Panel of Experts on Food Security and Nutrition of the Committee on World Food Security, Rome.

61. De Gorter, H., Just, D.R. (2009). The economics of a blend mandate for biofuels. American Journal of Agricultural Economics, 91(3), 731-750.

62. Angelsen, A. (2010). Policies for reduced deforestation and their impact on agricultural production. Proceedings of the National Academy of Sciences of the United States of America, 107(46), 19639-19644.

63. Krausmann, F., Erb, K.H., Gingrich, S., Haberl, H., Bondeau, A., Gaube, V., et al. (2013). Global human appropriation of net primary production doubled in the 20th century. Proceedings of the National Academy of Sciences of the United States of America, 110(25), 10324-10329.

64. Tilman, D., Clark, M. (2014). Global diets link environmental sustainability and human health. Nature, 515(7528), 518-522.

65. Dorin, B., Hourcade, J.C., Benoit-Cattin, M. (2013). A world without farmers? The Lewis path revisited. WP 47-2013, CIRED, France. 
66. ten Brink, P. (Ed.). (2011). TEEB: the economics of ecosystems and biodiversity in national and international policy making. London: Earthscan Publishing House.

67. Suweis, S., Carr, J.A., Maritan, A., Rinaldo, A., D'Odorico, P. (2015). Resilience and reactivity of global food security. Proceedings of the National Academy of Sciences of the United States of America, 112(22), 6902-6907. 
Figure 1. Relationship between biodiversity and yield

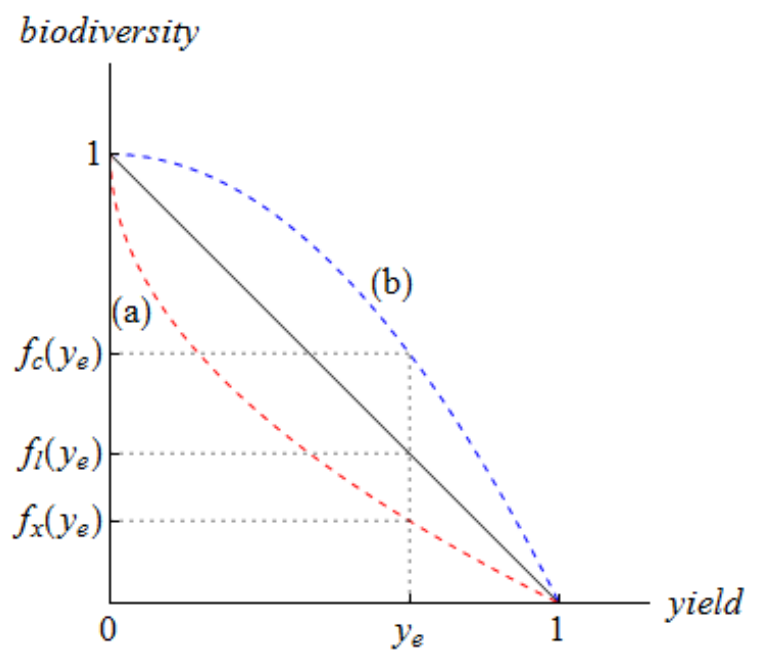

Legend: Biodiversity per unit of land is a decreasing function of yield, which may be linear (plain line, $f_{l}\left(y_{e}\right)=1-y$ ), convex (dashed curve $a$, here in the case of $f_{x}(y)=1-y^{1 / 2}$ ), or concave (dashed curve $b$, here in the case of $f_{c}(y)=1-y^{2}$ ). The figure shows the biodiversity levels obtained in these three cases for a yield level $y_{e}$. 
Figure 2. Producer and consumer surpluses

(a) Producer surplus

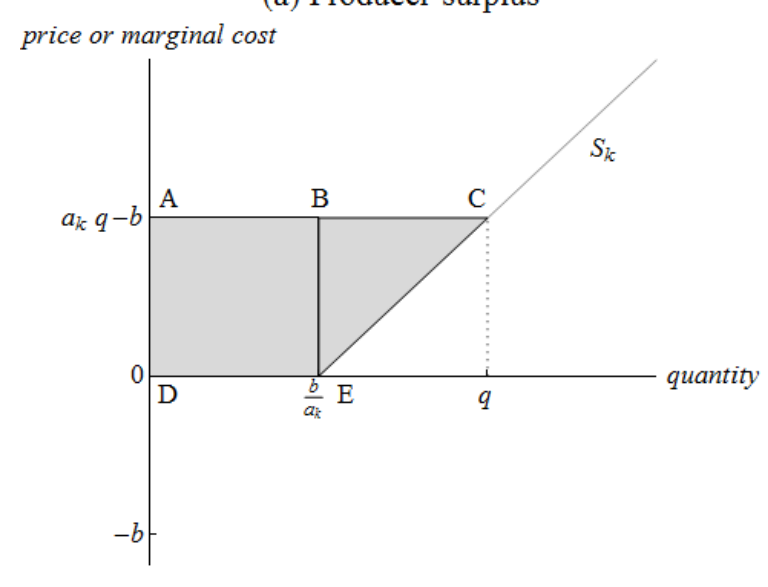

(b) Consumer surplus

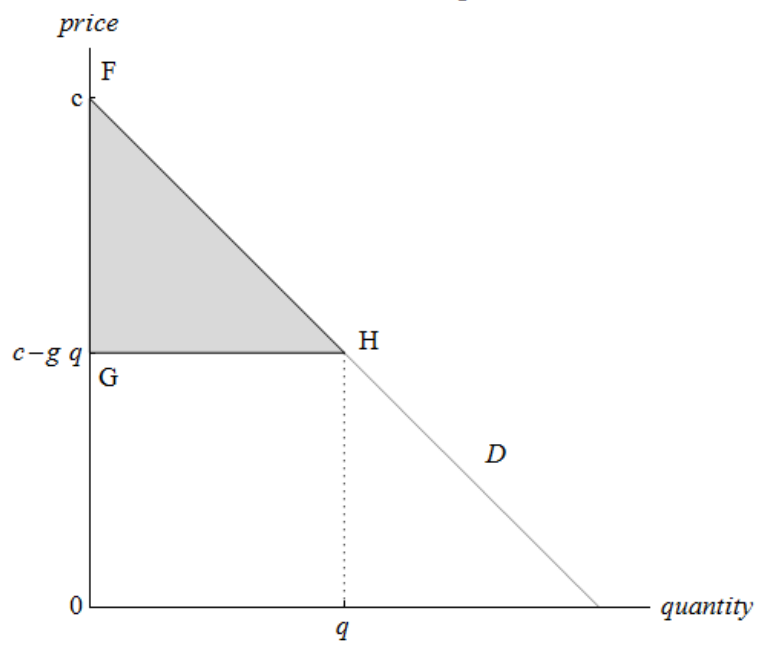

Legend: (a) Producer surplus is drawn in a quantity / price or marginal cost space. The inverse supply curve $S_{k}$ intersects the $p$-axis at $b / a_{k}$ and, therefore, represents the marginal cost of production for $q \geq b / a_{k}$. As a classical consequence of the linear approximation, given $b>0$, our model assumes that any quantity between 0 and $b / a_{k}$ is produced at no cost, whereas quantities above $b / a_{k}$ are produced at a positive and increasing marginal cost. Based on the inverse supply function $S_{k}$, a quantity $q$ is produced at a price $a_{k} q-b$. Producer surplus is determined by the sum of the areas of rectangle ABED, which is equal to $\left(a_{k} q-b\right) b / a_{k}$, and of triangle BCE, which is equal to $\left(a_{k} q-b\right)\left(q-b / a_{k}\right) / 2$.

(b) Consumer surplus is drawn in a quantity / price space. Based on the inverse demand function $D$, which represents the consumers' willingness to pay, a quantity $q$ is consumed at a price $c-g q$. Consumer surplus is determined by the triangle FGH, which measures the area between the consumers' willingness to pay and the equilibrium price. 
Figure 3. Equilibrium with perfectly inelastic demand

(a) Market

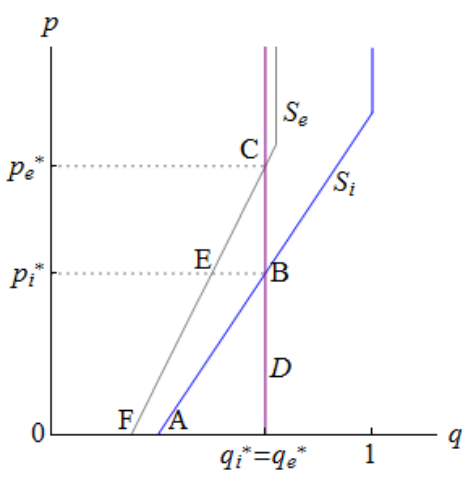

(b) Land use

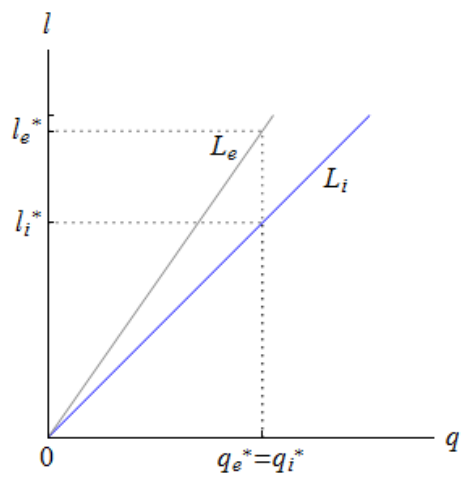

(c) Biodiversity

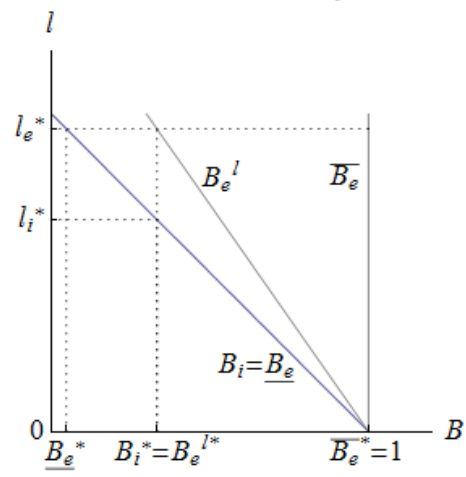

Legend: (a) Market equilibrium in quantity $(q) /$ price $(p)$ space. The demand function $D$ is perfectly inelastic (demand does not react to prices, which occurs under the conditions $c \rightarrow$ $+\infty$ and $g \rightarrow+\infty$ ). Other parameter values are $a_{i}=1.5, a_{e}=2, y_{e}=0.7, L=1$ and $c / g=2 / 3$. The figure depicts the quantity supplied and demanded at any given price and the equilibrium prices and quantities at the intersection of supply and demand functions for intensive and extensive farming. Under an intensive farming system (supply function $S_{i}$ ) in equilibrium, quantity is $q_{i}{ }^{*}$, price is $p_{i}{ }^{*}$, and producer surplus is $0 p_{i}{ }^{*} B A$. Under an extensive farming system (supply function $S_{e}$ ) in equilibrium, quantity is $q_{e}{ }^{*}=q_{i}{ }^{*}$, price is $p_{e}{ }^{*}$, and producer surplus is $0 p_{e}{ }^{*} C F$. Compared with intensive farming, global producer surpluses under extensive farming decrease by the area $E F A B$ but increase by the area $p_{e}{ }^{*} p_{i}{ }^{*} E C$ and have a positive balance; consumer surpluses decrease by the area $p_{e}{ }^{*} p_{i}{ }^{*} B C$; and total surpluses (producer and consumer) decrease by the area $C F A B$.

(b) Land use in quantity $(q) /$ land $(l)$ space. The land use functions $L_{i}$ under intensive farming and $L_{e}$ under extensive farming represent how much land is used with each farming method to produce any given quantity. Based on the equilibrium quantity $q_{e}{ }^{*}=q_{i}{ }^{*}$, the equilibrium land use is $l_{i}^{*}$ with intensive farming and $l_{e}{ }^{*}$ with extensive farming.

(c) Biodiversity conservation in biodiversity $(B) /$ land $(l)$ space. The figure represents three possible biodiversity functions for extensive farming depending on the trade-off between biodiversity and yield (see Table 1): $\underline{B}_{\mathrm{e}}$ if no biodiversity is conserved on land farmed extensively, $B_{e}{ }^{l}$ in the linear case, $\bar{B}_{\mathrm{e}}$ if all biodiversity is conserved on land farmed extensively. Based on the equilibrium land use $l_{e}{ }^{*}$, the equilibrium biodiversity level with extensive farming is $\underline{B}_{\mathrm{e}}{ }^{*}, B_{e}{ }^{{ }^{*}}$ and $\bar{B}_{\mathrm{e}}$ in each of these three cases. If land is farmed intensively, the equilibrium amount of biodiversity conservation $B_{i}{ }^{*}$ does not depends on the biodiversity function, and is determined by the biodiversity function $B_{i}$ (coinciding with $\underline{B}_{\mathrm{e}}$ ) based on the equilibrium land use $l_{i}^{*}$. 
Figure 4. Equilibrium with perfectly elastic demand

(a) Market

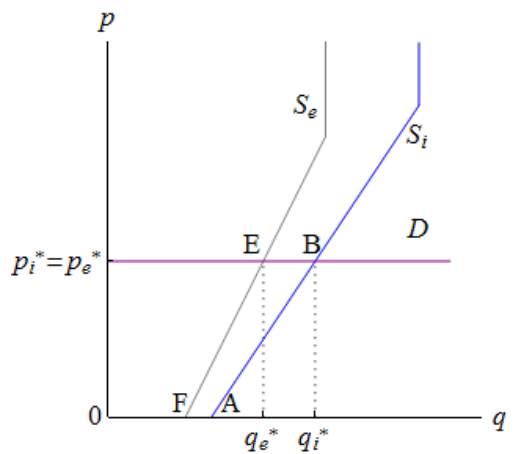

(b) Land use

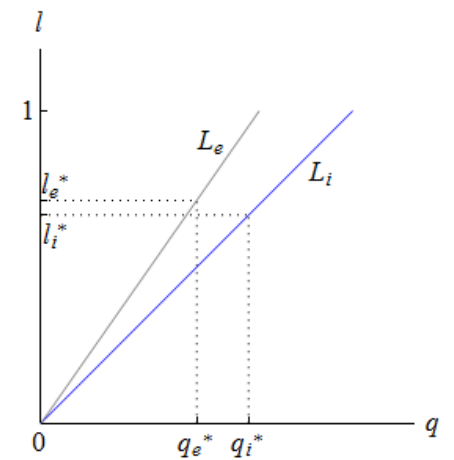

(c) Biodiversity

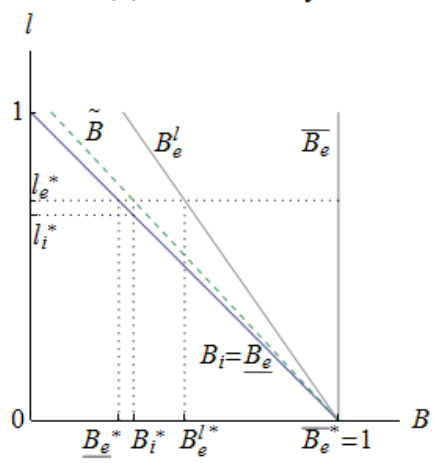

Legend: Changes relative to Figure 3. (a) Market equilibrium. The demand function $D$ is perfectly elastic (a price level occurs for which the quantity demanded is infinite under the condition $g=0$ ), with $c=2 / 3$. Under extensive farming in equilibrium, quantity is $q_{e}{ }^{*}$, price is $p_{e}{ }^{*}=p_{i}{ }^{*}$, and producer surplus is $0 p_{e}{ }^{*} E F$. Compared with intensive farming, the producer surplus decreases by the area $E F A B$ under extensive farming.

(c) The biodiversity function $\tilde{B}$ represents a convex relationship between biodiversity and yield such that in equilibrium, both farming systems yield the same level of biodiversity $\left(B_{e}\left(l_{e}^{*}\right)=B_{i}\left(l_{i}^{*}\right)\right)$. This equality is obtained for a convexity corresponding to $\tilde{\alpha}=0.19$ in the selected numerical case. 
Figure 5. Simulations of biodiversity levels under extensive vs. intensive farming depending on the degree of convexity of the biodiversity-yield relationship

(a) All simulations

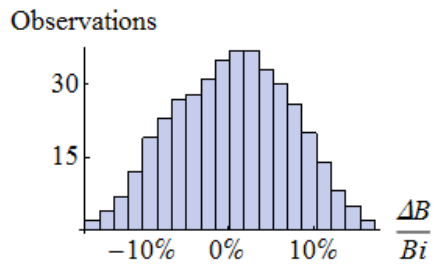

(b) Simulations with $\mathrm{f}(90 \%)=2 \%$ Observations

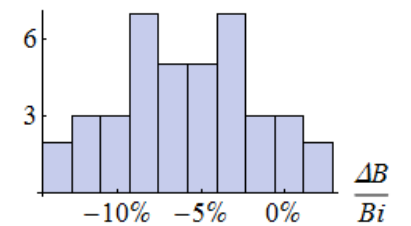

(c) Simulations with $\mathrm{f}(90 \%)=8 \%$ Observations

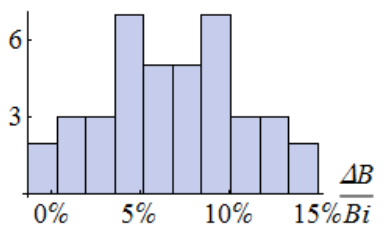

Legend: This figure gives the distribution of $\Delta B / B_{i}=\left(B_{e}-B_{i}\right) / B_{i}$, the percent variation of biodiversity when farming is extensive rather than intensive, in simulations performed with varying values of supply and demand elasticities and varying degrees of convexity of the biodiversity-yield relationship (40 simulations for each degree of convexity of the biodiversity-yield relationship, as drawn in (b) and (c), and 400 simulations in total, as drawn in (a)). The mean $m$ and standard deviation $s$ of the percent biodiversity change are as follows: (a) in all simulations, $m=-1.1 \%$ and $s=6.1 \%$; (b) in simulations where $f(90 \%)=2 \%$ (high degree of convexity of the biodiversity-yield relationship), $m=-7.4 \%$ and $s=2.8 \%$; and (c) in simulations where $f(90 \%)=8 \%$ (lower degree of convexity of the biodiversity-yield relationship), $m=5.3 \%$ and $s=2.7 \%$. Similar to the previously presented illustrations, we normalize the equilibrium with intensive farming to $p_{i}{ }^{*}=1 / 2$ and $q_{i}{ }^{*}=2 / 3$. For each simulation, the slopes and intercepts of the inverse intensive supply and demand, $b, c, a_{i}$ and $g$, are calculated to obtain the equilibrium $p_{i}{ }^{*}=1 / 2$ and $q_{i}{ }^{*}=2 / 3$ based on a supply elasticity $\varepsilon_{s i}=p_{i}{ }^{*} /\left(a_{i} q_{i}{ }^{*}\right) \in\{0.09,0.14\}$, demand elasticity $\varepsilon_{d}=-p_{i}{ }^{*} /\left(g q_{i}{ }^{*}\right) \in\{-0.07,-0.03\}$ and equilibrium relation $p_{i}{ }^{*}=a_{i} q_{i}{ }^{*}-b=c-g q_{i}{ }^{*}$. By assumption, under extensive farming, the yield is $y_{e}=0.9$ and the biodiversity function is $f(0.9)=1-0.9^{\alpha}$. The assumption that $\alpha \in[0,1)$ is equivalent to $0.9<0.9^{\alpha} \leq 1$, or $0 \leq 1-0.9^{\alpha}<0.1$, or equivalent to $0 \leq f\left(y_{e}\right)<10 \%$. Simulations are performed with ten equidistant values for $f\left(y_{e}\right)$ between $1 \%$ and $9 \%$. From equation (5), $a_{i}<a_{e}$. Based on the assumption that land use is higher with extensive farming rather than intensive farming, $g+a_{i}>\left(g+a_{e}\right) y_{e}$ (from Proposition 1) or $a_{e}$ $<a_{e}^{L}$, where $a_{e}^{L}=\left(g+a_{i}\right) / y_{e}-g$. Therefore, the extensive supply slope has to check $a_{i}<a_{e}$ $<a_{e}{ }^{L}$. We use ten equidistant values for $a_{e}$ between $1.1 a_{i}$ and $0.9 a_{e}{ }^{L}$ in the simulations. 
Figure 6. Equilibrium with land-use zoning

Intensive farming

(a) Market

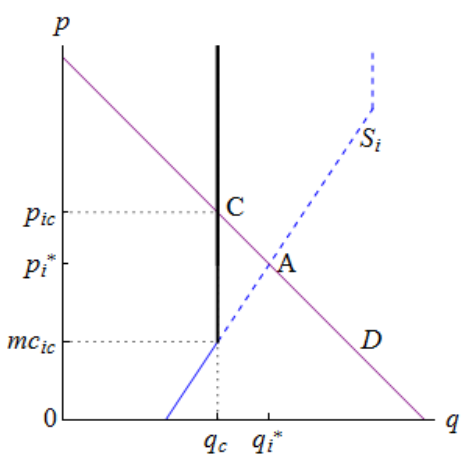

(d) Market

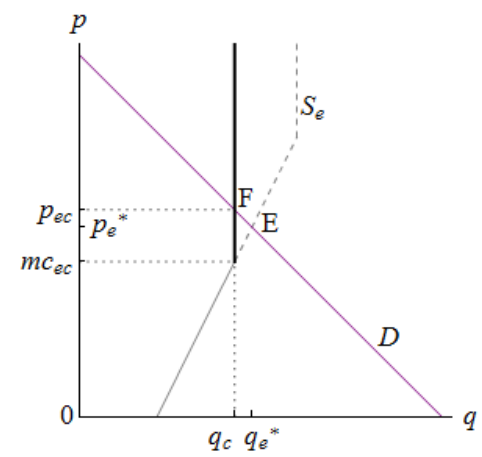

(b) Land use

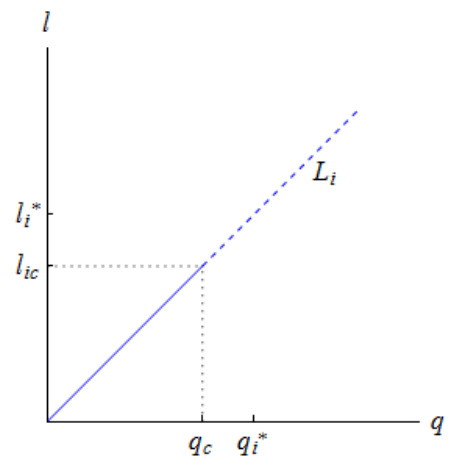

Extensive farming

(e) Land use

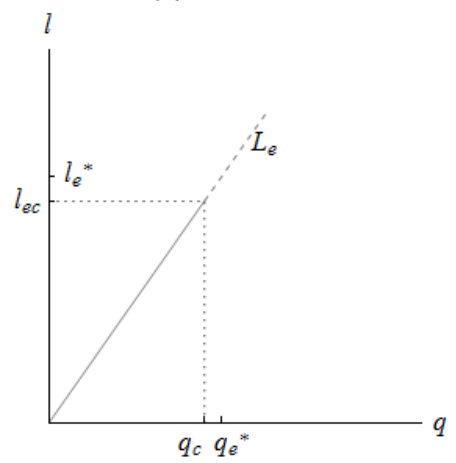

(c) Biodiversity

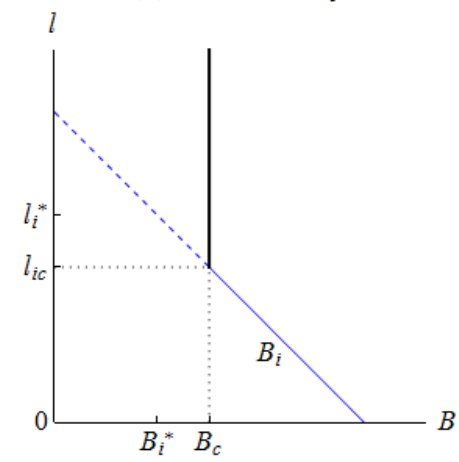

(f) Biodiversity

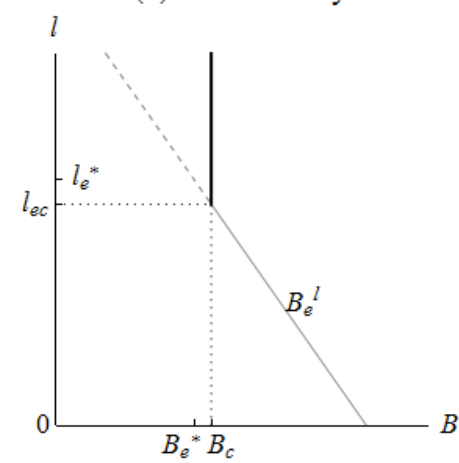

Legend: Equilibria with intensive farming [(a) to (c)] and extensive farming [(d) to (f)] are represented similarly to that in Figure 3. Only the case of a linear trade-off between biodiversity and yield is represented in (c) and (f). Without regulation, the intensive equilibrium is characterized by price $p_{i}{ }^{*}$ and quantity $q_{i}{ }^{*}$ at $\mathrm{A}(\mathrm{a})$, land use $l_{i}{ }^{*}$ (b) and biodiversity level $B_{i}{ }^{*}(\mathrm{c})$, whereas the extensive equilibrium is characterized by $p_{e}{ }^{*}$ and $q_{e}{ }^{*}$ at $\mathrm{E}(\mathrm{d}), l_{e}{ }^{*}$ (e) and $B_{e}{ }^{*}(\mathrm{f})$. With land-use zoning, the minimum cap on biodiversity is represented in (c) and (f) by the thick vertical line (thus, the dotted portions of the straight lines representing the trade-off between biodiversity and land use no longer apply). Such zoning imposes a cap on land use $l_{i c}$ with intensive farming and $l_{e c}$ with extensive farming. This cap on land use is equivalent to a maximum production quota $q_{\mathrm{c}}((\mathrm{b})$ and (e)). The market equilibrium is at the intersection of the demand curve and the thick vertical line representing the production restriction, i.e., at point $\mathrm{C}$ with intensive farming (a) and at point $\mathrm{F}$ with extensive farming (d). Under both farming systems, the equilibrium agricultural price ( $p_{i c}$ for intensive farming, and $p_{e c}$ for extensive farming) is higher than the equilibrium marginal cost of production $\left(m c_{i c}\right.$ for intensive farming, and $m c_{e c}$ for extensive farming). Incentives to encroach on conservation zones are higher for intensive than extensive farming $\left(p_{i c}-m c_{i c}>p_{e c}-m c_{e c}\right)$. 
Figure 7 Demand for food, feed, and biofuel goods

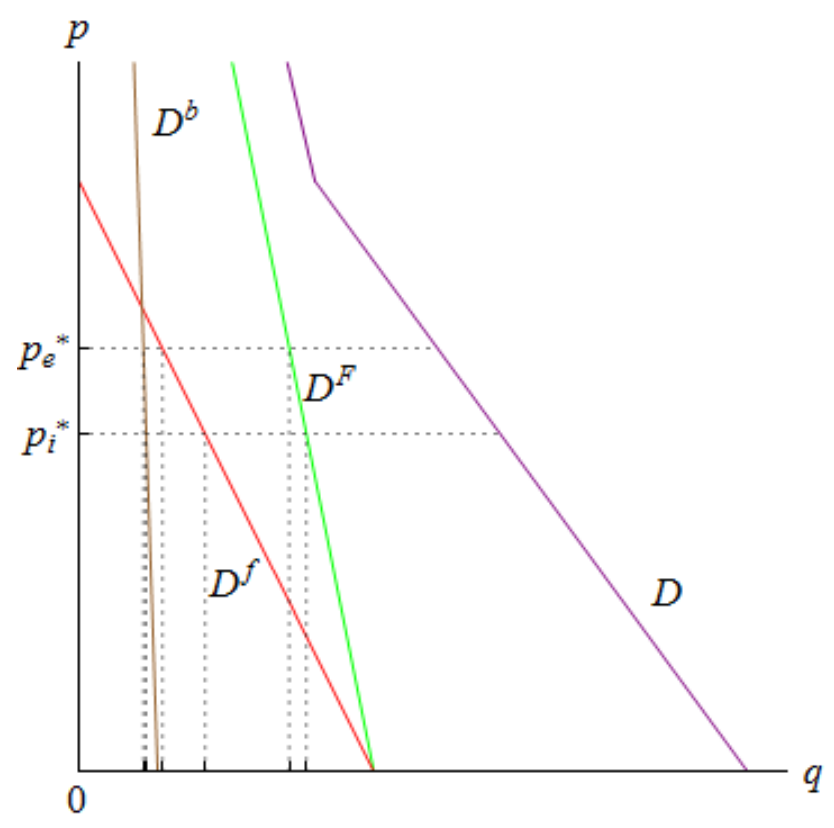

Legend: Demand functions in quantity / price space. Total demand $(D)$ is the horizontal sum of the biofuel demand $\left(D^{b}\right)$, feed demand $\left(D^{f}\right)$ and food demand $\left(D^{F}\right)$. Because the demand for biofuel is less price elastic than the demand for food (which is less price elastic than the demand for feed), $D^{b}$ has a higher slope than $D^{F}$, which in turn has a higher slope than $D^{f}$. The equilibrium price is $p_{e}{ }^{*}$ under extensive farming and $p_{i}{ }^{*}$ (lower) under intensive farming. For both farming systems and for each good, the equilibrium consumption level is determined by the intersection of the demand function, with the dotted line representing the equilibrium price level. Compared with intensive farming, extensive farming is characterized by a lower consumption level for each of the three goods. The decrease in consumption is higher for feed than for food and higher for food than for biofuel. The decrease in consumption is so small for biofuel, given the price inelasticity of its demand, that it is not possible to distinguish the ticks indicating the equilibrium levels of biofuel consumption with intensive and extensive farming in this figure. 